\title{
A Stereoselective Route to Polysubstituted Tetrahydroquinolines by Benzotriazole-Promoted Condensation of Aliphatic Aldehydes and Aromatic Amines
}

\author{
Sanjay Talukdar, ${ }^{\dagger}$ Chao-Tsen Chen, and J im-Min Fang* \\ Department of Chemistry, National Taiwan University, Taipei, Taiwan 106, Republic of China
}

Received J anuary 10, 2000

\begin{abstract}
By the promotion of benzotriazole (20 mol \%), two molecules of anilines (or other arylamines) and two molecules of phenylacetaldehyde (or o-bromophenylacetal dehyde) condensed to give a series of 1,2,3,4-tetrahydroquinolines in a stereoselective manner. By the catalysis of $\mathrm{Sml}_{2}$ or $\mathrm{Sml}_{3}$, the $\mathrm{N}$ - $(\alpha$-aminoal kyl)benzotriazol es derived from anilines and (R)-glycer al dehyde acetonide dissociated to the corresponding iminium and enamine species, which underwent asymmetric [4 +2$]$ cycloadditions to give optically active tetrahydroquinolines.
\end{abstract}

\section{Introduction}

The widespread applicability of benzotriazole as a synthetic auxiliary in a multitude of synthetic endeavors is well documented. ${ }^{1}$ Much of the chemistry of benzotriazol e originates from the ionization of an $\mathrm{N}$-( $\alpha$-aminoalkyl)benzotriazole $\mathbf{4}$ to an iminium ion $\mathbf{5}$ and benzotriazol ate anion (Figure 1$)$. In principle, an $\mathrm{N}$-( $\alpha$-aminoalkyl)benzotriazole can undergo nucleophilic substitution to give amines 7,2 or it can lose benzotriazole (BtH) to give enamines 6 on treatment with a base. ${ }^{3}$ These transformations may also proceed via iminium intermediate 5. For example, the imi nium intermediate $5(R=$ Et) can be trapped by ethyl vinyl ether to give the tetrahydroquinoline $\mathbf{8}(<20 \%$ yield) as a consequence of $[4+2]$ cycl oaddition. ${ }^{4}$

The [4 + 2] cycloadditions between $\mathrm{N}$-arylimines and dienophiles, giving tetrahydroquinolines (THQs) of medicinal and industrial importance, ${ }^{5}$ are often coined as imino Diels-Alder (IDA) reactions, ${ }^{6}$ although the reactions may not al ways proceed via a concerted mechanism. Lewis acids are generally used to promote the IDA reactions. ${ }^{7}$ Because the $\mathrm{N}$-alkylimines derived from ali-

† Permanent address: Scientific Officer, Bio-Organic Division, Bhabha Atomic Research Centre, Trombay, Mumbai - 400 085, India.

(1) F or review of the chemistry of benzotriazole, see: (a) Katritzky, A. R.; Rachwal, S.; Hitchings, G. J . Tetrahedron 1991, 47, 2683. (b) Katritzky, A. R.; Belyakov, S. A. Aldrichim. Acta 1998, 31, 35. (c) Katritzky, A. R.; Lan, X.; Yang, J . Z.; Denisko, O. V. Chem. Rev. 1998, $98,409$.

(2) Katritzky, A. R.; Racheal, B.; Rachwal, S. J . Chem. Soc., Perkin Trans. 1 1987, 805.

(3) Katritzky, A. R.; Long, Q.-H.; Lue, P.; J ozwiak, A. Tetrahedron 1990, 45, 8153.

(4) Katritzky, A. R.; Rachwal, B.; Rachwal, S. J . Org. Chem. 1995, 60, 2588.

(5) (a) Leeson, P. D.; Carling, R. W.; Moore, K. W.; Moseley, A. M.; Smith, J. D.; Stevenson, G.; Chan, T.; Baker, R.; Foster, A. C. Grimwood, S.; Kemp, J. A.; Marshall, G. R.; Hoogsteen, K. J . Med. Chem. 1992, 35, 1954. (b) Katritzky, A. R.; Rachwal, S.; Rachwal, B. Tetrahedron 1996, 52, 15031.

(6) F or reviews of imino Diels-Alder reactions, see: (a) Boger, D L.; Weinreb, S. M. Hetero Diels-Alder Methodology in Organic Synthesis; Academic: San Diego, 1987; Chapters 2 and 9. (b) Weinreb, S. M. Comprehensive Organic Synthesis; Trost, B. M., Fleming, I., Eds. Pergamon: Oxford, 1991; Vol. 5, 401-449. (c) Kobayashi, S. In Transition Metals for Organic Synthesis - Building Blocks and Fine Chemicals; Beller, M., Bolm, C., Eds.; Wiley-VCH: Weinheim, 1998; Vol. 1, 285-312.

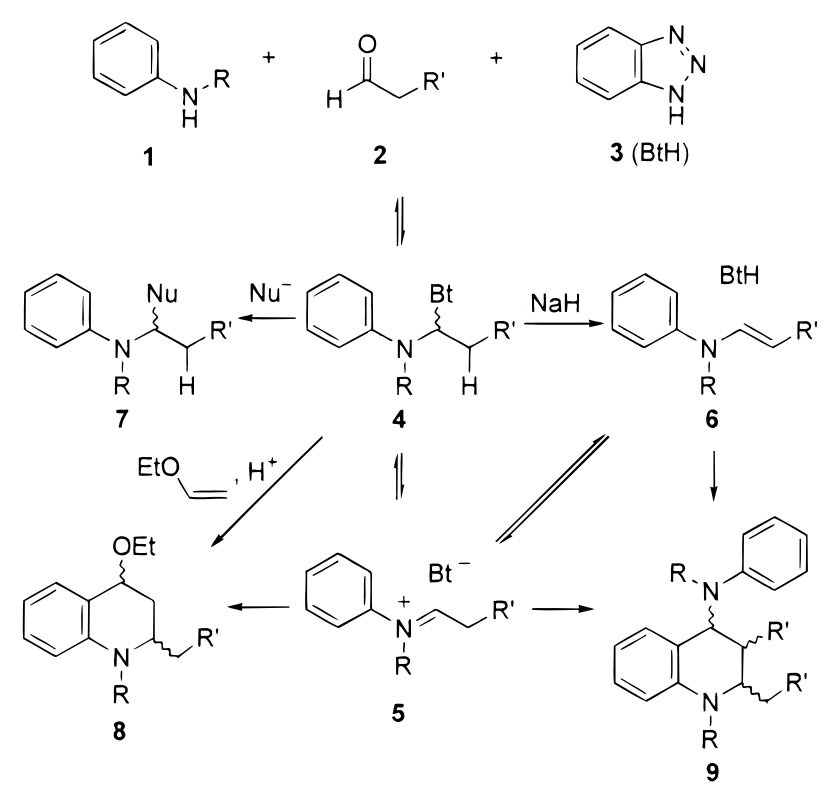

Figure 1. Benzotriazole-mediated condensation of anilines with aldehydes and the application to syntheses of amines and tetrahydroquinolines.

phatic aldehydes are unstable under acidic conditions, most examples of IDA reactions are limited to those (aralkylidene)anilines derived from aromatic al dehydes. ${ }^{7}$ From the IDA reactions of imines, one can only obtain the THQ products without an N-substituent. Another major drawback of these protocols is that excess amounts of external dienophiles are usual ly required for the IDA reactions. The above problems can be circumvented by using $\mathrm{N}$-( $\alpha$-anilinoalkyl)benzotriazoles $(\mathbf{4}, \mathrm{R} \neq \mathrm{H})$ as an

(7) For representative examples of imino Diels-Alder reactions, see: (a) Narasaka, K.; Shibata, T. Heterocycles 1993, 35, 1039. (b) Kobayashi, S.; I shitani, H.; Nagayama, S. Chem. Lett. 1995, 423. (c) Ishitani, H.; Kobayashi, S. Tetrahedron Lett. 1996, 37, 7357. (d) Annunziata, R.; Cinquini, M.; Cozzi, F.; Molteni, V.; Schupp, O. Tetrahedron 1997, 53, 9715. (e) Babu, G.; Perumal, P. T. Tetrahedron Lett. 1998, 39, 3225. (f) Hadden, M.; Stevenson, P. J . Tetrahedron Lett. 1999, 40, 1215. (g) Batey, R. A.; Simoncic, P. D.; Lin, D.; Smyj. P.; Lough, A. J . Chem. Commun. 1999, 651. (h) Ma, Y.; Qian, C.; Xie, M.; Sun. J. J . Org. Chem. 1999, 64, 6462. 
Table 1. Formation of Tetrahydroquinoline 9a by the Benzotriazole-Promoted Coupling Reaction of Aniline (2 equiv) and Phenylacetaldehyde ( 2 equiv)

\begin{tabular}{|c|c|c|c|c|c|c|}
\hline entry & $\begin{array}{l}\text { BtH, } \\
\text { mol \% }\end{array}$ & solvent & $\begin{array}{l}\text { reaction } \\
\text { temp, }{ }^{\circ} \mathrm{C}\end{array}$ & $\begin{array}{l}\text { reaction } \\
\text { time, } h\end{array}$ & $\begin{array}{c}\text { 9a, } \\
\text { yield, \% }\end{array}$ & $\begin{array}{l}\text { ratio of } \\
\text { isomers }\end{array}$ \\
\hline 1 & 0 & $\mathrm{EtOH}$ & 25 & 32 & 14 & $64: 36$ \\
\hline 2 & 100 & EtOH & 25 & 8 & 18 & 72:28 \\
\hline 3 & 80 & EtOH & 25 & 8 & 76 & $74: 26$ \\
\hline 4 & 60 & $\mathrm{EtOH}$ & 25 & 8 & 78 & $76: 24$ \\
\hline 5 & 40 & $\mathrm{EtOH}$ & 25 & 8 & 76 & 72:28 \\
\hline 6 & 20 & $\mathrm{EtOH}$ & 25 & 8 & 86 & $76: 24$ \\
\hline 7 & 10 & $\mathrm{EtOH}$ & 25 & 8 & 81 & $75: 25$ \\
\hline 8 & 5 & EtOH & 25 & 10 & 70 & $73: 27$ \\
\hline 9 & 2 & $\mathrm{EtOH}$ & 25 & 10 & 65 & $75: 25$ \\
\hline 10 & 100 & $\mathrm{EtOH}$ & $0-5$ & 0.5 & b & b \\
\hline 11 & 20 & $\mathrm{CH}_{2} \mathrm{Cl}_{2}$ & 25 & 24 & b & b \\
\hline 12 & 20 & $\mathrm{Et}_{2} \mathrm{O}$ & 25 & 24 & b & b \\
\hline
\end{tabular}

a The ratio of 2,3-trans-2,4-cis and 2,3-cis-2,4-cis isomers was determined by ${ }^{1} \mathrm{H}$ NMR analysis of the crude product $9 a .{ }^{b}$ No THQ 9a was observed, but the intermediary Bt-derivative 4 a was isolated.

in situ source of $\mathrm{N}$-aryl-N-alkyliminium ions, ${ }^{8}$ which are even more reactive species than $\mathrm{N}$-arylimines in the IDA reactions (Figure 1$)^{9}$

The chemistry utilizing the in situ formation of enamines from $\mathrm{N}$ - $(\alpha$-ami noal kyl)benzotriazol es has not been thoroughly explored. ${ }^{3}$ We conceived that a suitably designed $\mathrm{N}$-(anilinoalkyl)benzotriazole such as 4 could generate an iminium ion $\mathbf{5}$, wherein a facile isomerization to enamine $\mathbf{6}$ would feasible by the catalysis of the regenerated benzotriazolate ion $\left(\mathrm{pK}_{\mathrm{a}} \sim 8.0\right.$ for $\left.\left.\mathrm{BtH}\right)\right)^{1 \mathrm{a}}$ Under such circumstances, one could expect a facile IDAtype reaction to occur between the iminium ion (as the electron-deficient azadiene) and enamine (as the electronrich dienophile). ${ }^{10}$ Thus, two molecules of arylamine $\mathbf{1}$ and two molecules of aldehyde $\mathbf{2}$ could condense to give THQs 9. This idea is demonstrated herein by using the selected al iphatic al dehydes such as phenylacetal dehyde (2a), (2-bromophenyl)acetal dehyde (2b), and (R)-glyceral dehyde acetonide (2c) for the synthesis of various THQs $\mathbf{9 a}-\mathbf{n}$.

\section{Results and Discussion}

We first studied the reaction between aniline (1a) and phenylacetal dehyde (2a) (Table 1). In the absence of BtH (entry $\mathbf{1}$ ), the condensation of $\mathbf{1} \mathbf{a}$ and $\mathbf{2} \mathbf{a}$ only afforded a low yield (14\%) of THQ 9a after stirring for a prolonged period (32 h) in EtOH at room temperature. The yield and rate in formation of THQ 9a were greatly enhanced by using BtH as the promoter. When a mixture of $\mathbf{1 a}$ and $\mathbf{2 a}$ was stirred with a stoichiometric amount of $\mathrm{BtH}$ in EtOH for $8 \mathrm{~h}$ at room temperature, the THQ 9a was isolated in $78 \%$ yield (entry 2 ). A comprehensive study on such BtH-promoted condensation indicated that both

(8) Katritzky, A. R.; Nichols, D. A.; Qi, M.; Yang, B. J . Heterocyd. Chem. 1997, 34, 1259.

(9) J encks, W. P. Prog. Phys. Org. Chem. 1964, 2, 63.

(10) For acid-catalyzed [4 + 2] cycl oadditions between enamines and (benzylidene)anilines, see: Nomura, Y.; Kimura, M.; Takeuchi, Y.; Tomoda, S. Chem. Lett. 1978, 267. For a condensation between $\mathrm{N}$-methylaniline and hydroxyacetaldehyde, see: Turner, A. B.; McBain, B. I.; Howie, R. A. J. Chem. Soc., Perkin Trans. 1 1986, 1151. The reaction has been conducted in $\mathrm{EtOH}$ at $20^{\circ} \mathrm{C}$ for $48 \mathrm{~h}$ to give a single 2,3-cis-2,4-trans isomer of 3-hydroxy-2-hydroxymethyl-1-methyl-4-(Nmethylanilino)-1,2,3,4-tetrahydroquinoline in $45 \%$ yield. The stereochemistry is different from that of THQ 9f with the 2,3-trans-2,4-cis configuration obtained by condensation of $\mathrm{N}$-methylaniline and phenylacetaldehyde (our present investigation).
Table 2. One-Pot Synthesis of THQs $9 a-i$ in EtOH by Using Benzotriazole (20 mol \%) as the Promoter (Scheme 1)

\begin{tabular}{|c|c|c|c|c|c|c|}
\hline entry & $\begin{array}{l}\text { aryl- } \\
\text { amine }\end{array}$ & aldehyde & $\begin{array}{l}\text { reaction } \\
\text { time, h }\end{array}$ & $\begin{array}{l}\text { reaction } \\
\text { temp, }{ }^{\circ} \mathrm{C}\end{array}$ & $\begin{array}{l}\text { products } \\
\text { (yield, \%) }\end{array}$ & $\begin{array}{l}\text { ratio of } \\
\text { isomers }\end{array}$ \\
\hline 1 & $1 a$ & $2 a$ & 8 & 25 & $9 \mathbf{a}(86)$ & $76: 24$ \\
\hline 2 & $\mathbf{1 b}$ & $2 a$ & 2 & 25 & 9b (78) & $80: 20$ \\
\hline 3 & 1c & $2 a$ & 1 & 25 & 9c (78) & $95: 5$ \\
\hline 4 & 1c & $2 a$ & 1 & $0-5$ & $\mathbf{9 c}(80)$ & $100: 0^{b}$ \\
\hline 5 & Id & $2 a$ & 16 & 25 & 9d (80) & $77: 23$ \\
\hline 6 & le & $2 a$ & 2.5 & $0-5$ & 9e (88) & $100: 0^{b}$ \\
\hline 7 & If & $2 a$ & 3.5 & 25 & gf (68) & $100: 0^{b}$ \\
\hline 8 & $1 g$ & $2 a$ & 2 & 25 & $9 \mathbf{g}(88)$ & $100: 0^{b}$ \\
\hline 9 & 1h & $2 a$ & 2.5 & 25 & 9h (78) & $100: 0^{b}$ \\
\hline 10 & 1c & $2 b$ & 1 & $0-5$ & $9 i(85)$ & $100: 0^{b}$ \\
\hline
\end{tabular}

a The ratio of 2,3-trans-2,4-cis and 2,3-cis-2,4-cis isomers was determined by the ${ }^{1} \mathrm{H}$ NMR analysis of the crude product mixtures. ${ }^{b}$ Only the 2,3-trans-2,4-cis isomer was found according to the ${ }^{1} \mathrm{H}$ and ${ }^{13} \mathrm{C}$ NMR analyses.

the reaction rate and diastereoselectivity were little influenced by the amount of $\mathrm{BtH}$ used. The best result ( $86 \%$ yield) was obtained by using $20 \mathrm{~mol} \%$ of $\mathrm{BtH}$ as the promoter (entry 6). However, as low as $2 \mathrm{~mol} \%$ of $\mathrm{BtH}$ was still effective to catalyze the formation of $\mathrm{THQ}$ 9a (entry 9).

It was anticipated that BtH acted as a synthetic auxiliary to generate the $\mathrm{N}$-(anilinoalkyl)benzotriazole intermediate. Such intermediate $\mathbf{4 a}$ was indeed isolated after aniline, phenylacetal dehyde, and benzotriazole were stirred in $\mathrm{EtOH}$ at $0{ }^{\circ} \mathrm{C}$ for a short period $(0.5 \mathrm{~h})$ or by using nonpolar solvents $\left(\mathrm{CH}_{2} \mathrm{Cl}_{2}\right.$ or $\left.\mathrm{Et}_{2} \mathrm{O}\right)$ other than $\mathrm{EtOH}$ (entries 10-12 of Table 1 ). Compound $\mathbf{4 a}$ thus changed to the THQ 9a on stirring in $\mathrm{EtOH}$ at room temperature. An IDA-type reaction of the intermediary iminium ion and enamine could account for the formation of 9 a. The BtH methodology provided an access to the more el ectrophilic iminium ions $\left(\mathrm{C}=\mathrm{N}^{+}\right)$, by comparison with the imines $(\mathrm{C}=\mathrm{N})$ obtained from the normal condensation of aldehydes and amines. The benzotriazolate ion also facilitated the formation of enamines, which functioned as the requisite dienophiles in the IDA-type reactions. Hence, BtH effectively promoted the condensation between aniline and phenylacetaldehyde (an enolizable al dehyde) without the assistance of any Lewis acid.

The THQ product 9a existed as a mixture of two isomers, which were separated by silica gel column chromatography. The structures of isomers were established by the ${ }^{1} \mathrm{H}$ NMR analyses including those of NOESY and NOE difference spectra. Each isomer showed an NOE correlation between $\mathrm{H}-2$ and $\mathrm{H}-4$, indicating their cis relationship. The $\mathrm{H}-3$ of the major isomer exhibited at $\delta 3.07$ as a triplet with large coupling constant $(\mathrm{J}=9.7 \mathrm{~Hz})$, whereas the $\mathrm{H}-3$ of the minor isomer appeared at $\delta 3.29$ as a broad doublet with small coupling constant $(\mathrm{J}=3.0 \mathrm{~Hz})$. The major isomer was thus assigned to have a 2,3-trans-2,4-cis configuration with all the C-2, C-3, and C-4 protons on nearly axial positions, whereas the minor isomer was determined to be the C-3 epimer with a 2,3-cis-2,4-cis configuration. Irradiation of the $\mathrm{H}-3$ in minor isomer caused significant enhancements of the signals of $\mathrm{H}-2$ (19\% NOE) and $\mathrm{H}-4$ (7\% NOE), in agreement with the all cis configuration.

The initial recipe for the $\mathrm{BtH}$-promoted one-pot synthesis of THQs was successfully applied to the IDA-type reactions using other arylamines (Table 2 ), such as the 
substituted anilines $\mathbf{1 b}-\mathbf{f}$ (Scheme 1), 1-naphthylamine (1g, eq 1) and 2-fluorenamine (1h, eq 2). For those C-3-
2<smiles>Nc1cccc2ccccc12</smiles><smiles>O=C(O)CC(=O)c1ccccc1</smiles>

19

2<smiles></smiles>

9g

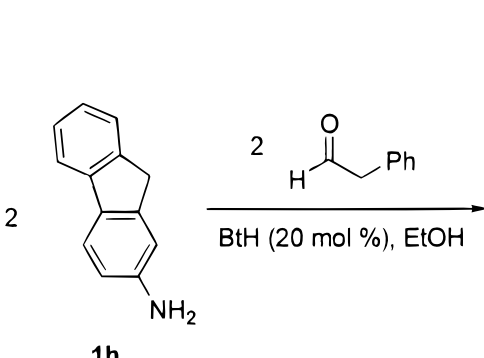

1h

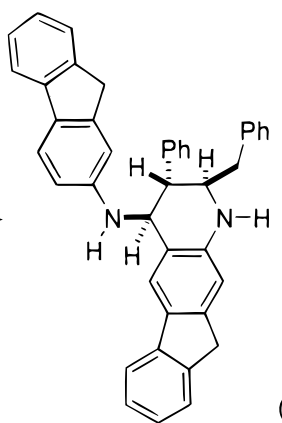

(2)
(1)

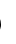

substituted anilines $\mathbf{1 b}$,c and (3,4-methylenedioxy)aniline 1e, the IDA-type reactions occurred exclusively at C-6 rather than $\mathrm{C}-2$ positions as a consequence of steric effects. The anil ines with electron-donating groups, such as methyl, methoxy, and methylenedioxy substituents, tended to yield the corresponding THQs in a much shorter time (compared entries 2 and 3 with entry 1 in Table 2). Thus, the IDA-type reactions with 3-methoxyaniline or (3,4-methylenedioxy)aniline could be conducted even at a low temperature $\left(0^{\circ} \mathrm{C}\right)$ to give the desired THQ products (Table 2, entries 4 and 6). On the other hand, the IDA-type reaction using 4-chloroaniline required a long period (16 h) at room temperature for completion (Table 2, entry 5). No THQ product was obtained by stirring 3,4-dichloroaniline and phenylacetaldehyde with $\mathrm{BtH}(20 \mathrm{~mol} \%)$ in $\mathrm{EtOH}$ for $24 \mathrm{~h}$; instead, the intermediary N-[1-(3,4-dichloroanilino)-2-phenylethyl]benzotriazole was isolated in $18 \%$ yield. The IDA-type reaction of 3-methoxyaniline with (2-bromophenyl)acetaldehyde was also realized by the catalysis of $\mathrm{BtH}$ at $0{ }^{\circ} \mathrm{C}$ to give the THQ $9 \mathbf{i}$ in $85 \%$ yield (eq 3 and entry 10 of Table 2),
2

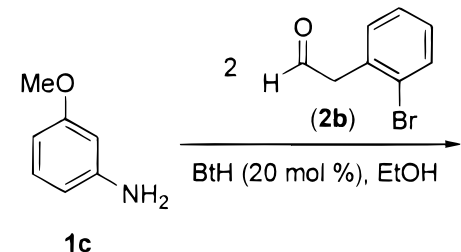

$1 c$

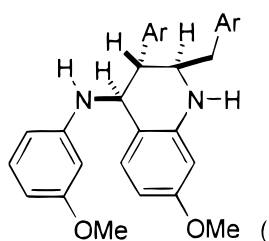

9i $\left(\mathrm{Ar}=\mathrm{O}-\mathrm{BrC}_{6} \mathrm{H}_{4}\right)$ whereas the less reactive aniline (1a) afforded only the condensation with (2-bromophenyl)acetaldehyde and BtH to give N-[1-anilino-2-(2-bromophenyl)ethyl ]benzotriazole even by stirring for a prolonged period at room temperature.
Scheme 1

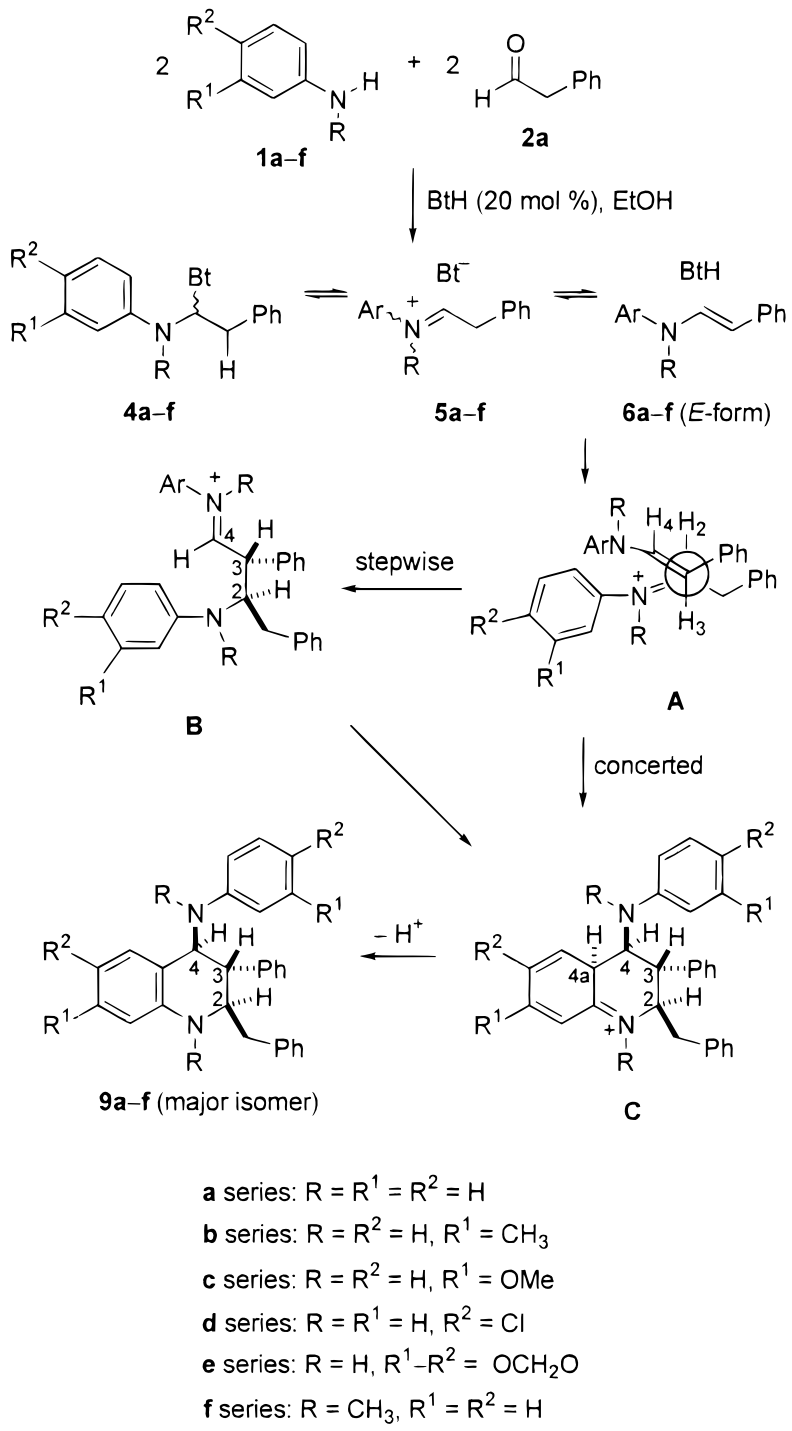

The IDA reactions occurred in a highly stereoselective manner when electron-rich anilines were used. According to the ${ }^{1} \mathrm{H}$ and ${ }^{13} \mathrm{C}$ NMR analyses of the THQ products, the 2,3-trans-2,4-cis isomers al ways corresponded to the major or exclusive products. The minor isomers, if they existed, always exhibited the 2,3-cis-2,4-cis configuration. The IDA-type reactions of $\mathrm{N}$-methylaniline, 1-naphthylamine, and 2-fluorenamine with phenylacetaldehyde afforded, respectively, the THQs $\mathbf{9 f}, \mathbf{9 g}$, and $\mathbf{9 h}$ exclusively with the 2,3-trans-2,4-cis configuration (Table 2, entries 7-9). Their C-3 protons displayed as triplets with large coupling constants $(8.5-9.5 \mathrm{~Hz})$, a characteristic of three adjacent axial protons as that found in the $9 a-$ major isomer. An X-ray diffraction analysis of 9 f further confirmed its 2,3-trans-2,4-cis configuration. ${ }^{10,11}$

The IDA reactions might proceed via either concerted ${ }^{8}$ or stepwise ${ }^{6 b}$ mechanisms (Scheme 1 ). According to the

(11) Single crystals of $9 f\left(\mathrm{C}_{30} \mathrm{H}_{30} \mathrm{~N}_{2}, \mathrm{M}=418.56\right)$ were obtained via slow evaporation of a solution of $\mathbf{9 f}$ in EtOAc-cyclohexane, in a closed chamber saturated with hexane. Crystal data for 9f: triclinic, a = $10.183(5) \AA, b=10.920(4) \AA, c=11.737(4) \AA, V=1157.6(8) \AA^{3}$, crystal size $0.2 \times 0.15 \times 0.1 \mathrm{~mm}, \mathrm{~T}=296 \mathrm{~K}$, space group $\mathrm{P} 1, \mathrm{Z}=2$, absorption coefficient $=0.070 \mathrm{~mm}^{-1}$, reflections collected 8761 , independent reflections $4039\left(R_{\text {int }}=0.0261\right)$. Final $R$ indices $R 1=0.0506$, wR2 $=$ 0.1330 , $R$ indices (all data) $R 1=0.0791$, wR2 $=0.1523$. Refinement method: full-matrix least-squares on $\mathrm{F}^{2}$. 


\section{Scheme 2}

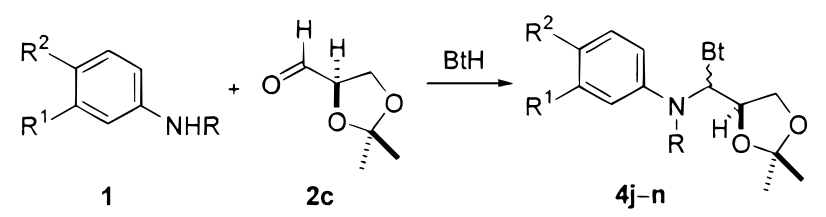

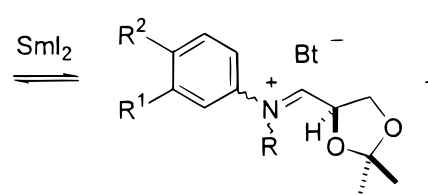

$5 j-n$

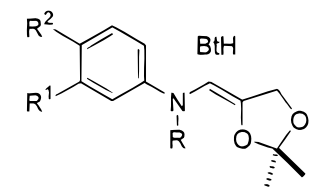

$6 \mathrm{j}-\mathrm{n}$ (Z-form)

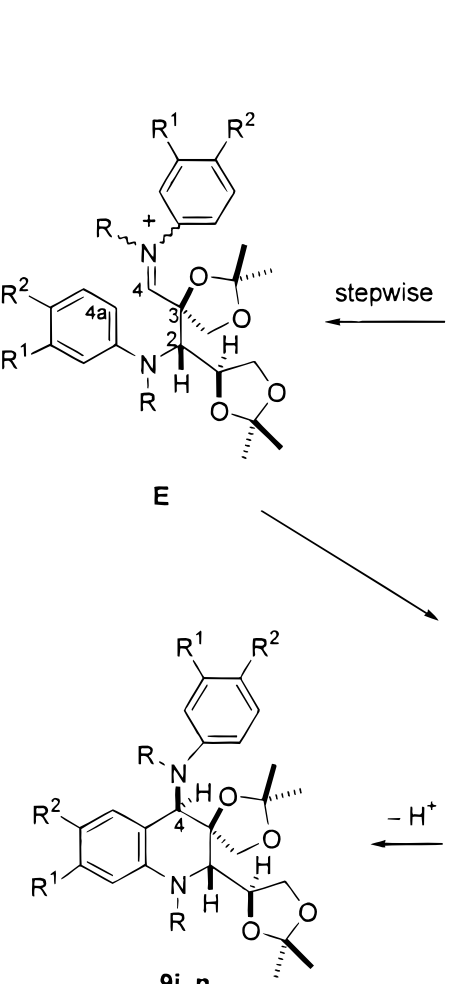

$9 j-n$

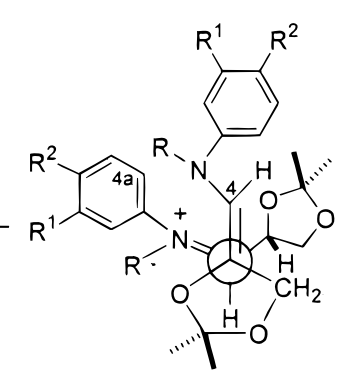

D concerted

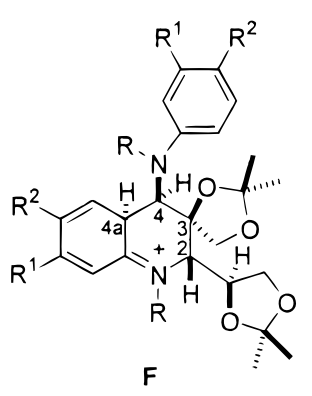

stereochemical outcomes, transition state $\mathbf{A}$ might involve in the cycloaddition reaction of the intermediary iminium ion $(\mathbf{5 a}-\mathbf{f})$ and enamine $(\mathbf{6 a}-\mathbf{f})$. As shown in transition state $\mathbf{A}$, the enamine species with the (E)-configuration would add to the iminium ion in a synclinal orientation. The subsequent aromatization of the intermediate $\mathbf{C}$ would yield the major THQ products $\mathbf{9 a}-\mathbf{f}$ with 2,3-trans2,4-cis configuration. Transition state $\mathbf{A}$ was presumably favored due to the lower steric demand and the stabilization by an electrostatic interaction between the enamine $\mathrm{N}$-center and the iminium $\mathrm{N}$-center. Scheme 1 also depicts the stepwise mechanism via an intramolecular cyclization of the intermediate $\mathbf{B}$ to the THQ products. As shown in Table 1, the THQ formation appeared to be faster by using the anilines with electron-donating groups (1b, 1c, and $\mathbf{1 e}$ ) and slower by using 4-chloroaniline (1d). This tendency was consistent with the reactivity in
Table 3. Lewis Acid-Promoted Transformation of $4 \mathbf{j}-\mathbf{n}$ to THQs 9j-n in THF Solution (Scheme 2)

\begin{tabular}{|c|c|c|c|c|}
\hline entry & substrate & $\begin{array}{l}\text { Lewis acid } \\
(\text { mol \%) }\end{array}$ & $\begin{array}{l}\text { reaction } \\
\text { time, h }\end{array}$ & $\begin{array}{l}\text { products } \\
\text { (yield, \%) }\end{array}$ \\
\hline 1 & $4 ;$ & none & 16 & $\mathrm{a}$ \\
\hline 2 & $\mathbf{4 j}$ & $\mathrm{Sml}_{3}(10)$ & 16 & 9j (80) \\
\hline 3 & 4 & $\mathrm{Sml}_{2}(10)$ & 16 & 9 ( $(88)$ \\
\hline 4 & $\mathbf{4 j}$ & $\mathrm{Sml}_{2}(50)$ & 16 & 9j (73) \\
\hline 5 & $\mathbf{4 j}$ & $\mathrm{Sml}_{2}(100)$ & 16 & 9j (74) \\
\hline 6 & 4 & $\mathrm{SmCl}_{3}(10)$ & 48 & 9j (64) \\
\hline 7 & $4 j$ & $\mathrm{TiCl}_{4}(10)$ & 24 & 9j (32) \\
\hline 8 & 4 & silica gel ${ }^{b}$ & 16 & a \\
\hline 9 & $4 \mathbf{k}$ & $\mathrm{Sml}_{2}(10)$ & 16 & $9 \mathbf{k}(65)$ \\
\hline 10 & 4I & $\mathrm{Sml}_{2}(10)$ & 16 & 9l (64) \\
\hline 11 & $4 m$ & $\mathrm{Sml}_{2}(10)$ & 16 & $9 m(64)$ \\
\hline 12 & $4 n$ & $\mathrm{Sml}_{2}(10)$ & 16 & $9 n(68)$ \\
\hline
\end{tabular}

a Starting material 4j was recovered quantitatively. ${ }^{\mathrm{b}}$ Silica gel 60 was used (Merck, $0.063-0.200 \mathrm{~mm}$, three times by weight of 4j).

aromatic el ectrophilic substitutions of B. One might al so argue that the high reactivity and stereosel ectivity in the IDA-type reactions of the more robust amines $\mathbf{l f}-\mathbf{h}$ were attributable to the electronic factors and steric congestion.

To advance this strategy to the asymmetric synthesis of THQs, we also investigated the IDA-type reactions of anilines and (R)-glyceral dehyde acetonide (2c). ${ }^{12}$ Aniline (2 equiv) reacted with $\mathbf{2 c}$ (2 equiv) in refluxing $\mathrm{EtOH}$ in the presence of $\mathrm{BtH}(20 \mathrm{~mol} \%)$ to give the corresponding $\mathrm{N}$-(anilinoal kyl)benzotriazole $4 \mathrm{j}$ in $17 \%$ yield (Scheme 2 ). Even by increasing the amount of BtH to $100 \mathrm{~mol} \%$, the reaction was still arrested at the intermediate stage, giving $77 \%$ yield of $\mathbf{4 j}$, without the generation of any trace of the desired THQ product.

The success of using lanthanide salts in promotion of IDA reactions, ${ }^{7 b, d, g, h}$ and our experience of using samarium ions in aldol-Tishchenko reactions ${ }^{13}$ prompted us to evaluate the efficacy of samarium-based ${ }^{14}$ Lewis acids for the formation of THQs (Scheme 2 and Table 3). The formation of THQ 9j would depend on the simultaneous existence of iminium ion $\mathbf{5 j}$ and enamine $\mathbf{6 j}$. We anticipated that samarium ion would coordinate with the benzotriazole moiety to shift the equilibrium of $4 \mathbf{j}$ with 5j and $\mathbf{6 j}$ toward the desired direction for the formation of THQs. ${ }^{8}$

We were gratified to find that treatment of $\mathrm{N}$-(anilinoalkyl)benzotriazole $\mathbf{4 j}$ with $10 \mathrm{~mol} \%$ of $\mathrm{Sml}_{3}$ gave a single product 9 j in $80 \%$ yield (Table 3 , entry 2 ). The structure of THQ 9j was unambiguously established by an X-ray diffraction analysis. ${ }^{15}$ The yield of $\mathbf{9 j}$ was increased to $88 \%$ by using $10 \mathrm{~mol} \%$ of $\mathrm{Sml}_{2}$ as the catalyst. No competitive reductive coupling of $\mathbf{4 j}$ was found, ${ }^{16}$ even in the cases that $50 \%$ and $100 \%$ of $\mathrm{Sml}_{2}$ were used. The Lewis acids $\mathrm{SmCl}_{3}$ and $\mathrm{TiCl}_{4}$ were, however, less effective in conversion of $\mathbf{4 j}$ to $\mathbf{9 j}$. On

(12) Funabashi, M.; Yoshimura, J . Bull. Chem. Soc. J pn. 1968, 41, 2735. Dimerization of $\mathrm{N}$-phenyl (R)-glyceraldimine acetonide by the catalysis of acetic acid gives the THQ 9j (30\%) as a mixture of two isomers. This paper reported only one example, and the protocol was not generalized.

(13) Lu, L.; Chang, H.-Y.; Fang, J .-M. J . Org. Chem. 1999, 64, 843.

(14) Both the divalent and trivalent samarium species can act as hard Lewis acids to coordinate with hard Lewis bases such as oxygen and nitrogen atoms. See: Gu, X.; Curran, D. P. In Transition Metals for Organic Synthesis - Building Blocks and Fine Chemicals; Beller, M., Bolm, C., Eds.; Wiley-VCH: Weinheim, 1998; Vol. 1, pp 425-438.

(15) Single crystals of 9j $\left(\mathrm{C}_{24} \mathrm{H}_{30} \mathrm{~N}_{2} \mathrm{O}_{4}\right)$ and 9n $\left(\mathrm{C}_{24} \mathrm{H}_{26} \mathrm{Cl}_{4} \mathrm{~N}_{2} \mathrm{O}_{4}\right.$, containing a molecule of EtOAC) were obtained, respectively, via slow evaporation of the solutions of $\mathbf{9}$ and $\mathbf{9 n}$ in EtOAc-hexane, in closed chambers saturated with hexane. 
stirring with silica gel at room temperature for $16 \mathrm{~h}$, compound $4 \mathbf{j}$ was entirely recovered without any formation of 9 j.

This methodology provided an access to optically active 2,3,3,4-tetrasubstituted THQs $\mathbf{9 k}$ - $\mathbf{n}$ with further substitution on the nitrogen atoms and aromatic rings. The starting materials $\mathbf{4 k} \mathbf{- n}$ were prepared in $75-96 \%$ yields by condensation of stoichiometric amounts of benzotriazole, (R)-glyceraldehyde acetonide and appropriate anilines. The subsequent treatments of $\mathbf{4 k}-\mathbf{n}$ with $\mathrm{Sml}_{2}$ (10 mol \%) in THF solution afforded the desired THQs $\mathbf{9 k}-\mathbf{n}$ in fair yields. The $(2 \mathrm{~S}, 3 \mathrm{R}, 4 \mathrm{R})$ configuration of $\mathbf{9 n}$ was confirmed by an X-ray diffraction analysis. ${ }^{15}$ The same stereochemistry in $\mathbf{9 k} \mathbf{-} \mathbf{m}$ was proposed on the basis of the NMR analyses and mechanistic consideration. The ${ }^{1} \mathrm{H}$ NMR analyses of $9 \mathrm{j}$ by using chiral shift reagent $\mathrm{Eu}(\mathrm{tfc})_{3}(3 \%, 5 \%$ and $7 \mathrm{wt} \% \mathrm{~s})$ did not show the existence of its enantiomer. The HPLC examinations of 9j and 9n on a chiral column (Chiralcel OD), by elution with the gradients of 2-propanol and hexane, also indicated homogeneity of these samples.

One can interpret the stereochemical outcome in the formation of THQs $\mathbf{9 j}-\mathbf{n}$ by either concerted or stepwise mechanisms (Scheme 2). Coordination of samarium ion with the benzotriazol moiety in $\mathbf{4} \mathbf{j}-\mathbf{n}$ could induce the generation of iminium ions $\mathbf{5 j}-\mathbf{n}$ and enamines $\mathbf{6 j}-\mathbf{n}$. On the basis of less steric demand and stabilization by chelation of the nitrogen and oxygen atoms with samarium ion, enamine $\boldsymbol{6} \mathbf{j}-\mathbf{n}$ likely existed as the (Z)isomer. Although the enamine intermediate lost the chirality at the carbinyl center, the iminium component $(5 \mathbf{j}-\mathbf{n})$ still retained the required chirality to direct an enantioselective IDA-type reaction. Thus, the enamine attacked the aryliminium ion on the less hindered face to construct the $\mathrm{C} 2-\mathrm{C} 3$ and $\mathrm{C} 4-\mathrm{C} 4 \mathrm{a}$ bonds in a stereospecific manner. Transition state $\mathbf{D}$ having the oxygen atom in the proximity of the iminium ion would be stabilized, whereas the al ternative transition state having the $\mathrm{CH}_{2}$ group placed on the same side of $\mathrm{N}$-aryl group was disfavored due to the steric effect. The stepwise mechanism incorporates the formation of an intermediate $\mathbf{E}$ and the subsequent formation of $\mathrm{C} 4-\mathrm{C} 4 \mathrm{a}$ bond via the less hindered face of the iminium moiety.

In summary, we have accomplished a one-pot synthesis of various TH Qs by the benzotriazole-promoted "two-pair coupling" reactions of phenylacetal dehydes and aromatic amines. The present investigation explores the first application of $\mathrm{N}$-( $\alpha$-aminoalkyl)benzotriazoles involving the generation of $\mathrm{N}$-aryliminium ions and an in situ trapping with their counterparts of enamines, without using external dienophiles. We also demonstrate that the $\mathrm{N}$-( $\alpha$-aminoalkyl)benzotriazoles derived from various anilines and (R)-glyceraldehyde acetonide can undergo asymmetric IDA-type reactions by the catalysis of $\mathrm{Sml}_{2}$ or $\mathrm{Sml}_{3}$ to give optically active THQs. Combinatorial synthesis of THQs is also promising on the basis of our current methodology.

\section{Experimental Section}

General Procedures. Melting points are uncorrected. Optical rotations were measured on a digital polarimeter with

(16) Aurrecoechea, J . M.; Fernandez-Acebes, A. Tetrahedron Lett. 1992, 33, 4763. A stoichiometric amount of $\mathrm{Sml}_{2}$ has been reported to reduce the $\mathrm{N}$-( $\mathrm{N}^{\prime}, \mathrm{N}^{\prime}$-dialkylaminoalkyl)benzotriazoles derived from nonenolizable aldehydes to generate the amino $\alpha$-radical intermediates, which undergo a coupling reaction to give the corresponding 1,2diamines. a cuvette of $1 \mathrm{~cm}$ length. ${ }^{1} \mathrm{H}$ NMR spectra were recorded at 300 or $400 \mathrm{M} \mathrm{Hz}$ with $\mathrm{CHCl}_{3}\left(\delta_{\mathrm{H}} 7.24\right)$ as the internal standard; ${ }^{13} \mathrm{C} \mathrm{NMR}$ spectra were recorded at 75 or $100 \mathrm{MHz}$ with $\mathrm{CDCl}_{3}$ $\left(\delta_{\mathrm{C}} 77.0\right.$ (central line of $\left.\mathrm{t}\right)$ ) as the internal standard. Mass spectra were recorded at an ionizing voltage of 70 or $20 \mathrm{eV}$. Column chromatography was performed on silica gel (70-230 mesh); gradients of EtOAc and n-hexane were used as eluents. THF was distilled from sodium benzophenone ketyl under $\mathrm{N}_{2}$. (2-Bromophenyl)acetaldehyde was prepared by a known procedure ${ }^{17}$ from (2-bromophenyl)ethanol.

4-Anilino-2-benzyl-3-phenyl-1,2,3,4-tetrahydroquinoline (9a). A mixture of phenylacetal dehyde (600 $\mathrm{mg}, 5 \mathrm{mmol}$ ), aniline (465 mg, $5 \mathrm{mmol}$ ), and benzotriazole (119 mg, $1 \mathrm{mmol}$ ) in EtOH solution $(2 \mathrm{~mL})$ was stirred at $25^{\circ} \mathrm{C}$. The reaction mixture became yellow after $3 \mathrm{~h}$ stirring. The coupling reaction was complete after $8 \mathrm{~h}$ as shown by the TLC analysis. The reaction mixture was kept in an ice bath for $1 \mathrm{~h}$ to precipitate out the product. Filtration of the solids and washing with $\mathrm{Et}_{2} \mathrm{O}$ gave the THQ product 9 a ( $839 \mathrm{mg}, 86 \%)$ as a mixture of two isomers (2,3-trans-2,4-cis/2,3-cis-2,4-cis $=76: 24)$ as shown by the ${ }^{1} \mathrm{H}$ NMR analysis. The two isomers were separated by column chromatography $\left(\mathrm{SiO}_{2}\right)$ using EtOAc/hexane (10:90) as the eluent.

The reaction using a stoichiometric amount of benzotriazole, according to the above-mentioned procedure, gave $9 \mathbf{a}$ (78\%) as a mixture of two isomers (2,3-trans-2,4-cis/2,3-cis-2,4-cis = 72:28). The mother liquor and washings, after drying $\left(\mathrm{Na}_{2} \mathrm{SO}_{4}\right)$ and removal of solvents, did not indicate the presence of any 9a isomers according to the ${ }^{1} \mathrm{H}$ NMR analysis.

When equal molar amounts of phenylacetal dehyde, aniline, and benzotriazole were stirred in EtOH $(2 \mathrm{~mL})$ at $0-5{ }^{\circ} \mathrm{C}$ for $0.5 \mathrm{~h}$, the intermediate $\mathrm{N}$-(1-anilino-2-phenylethyl)benzotriazole (4a) was obtained (70\%) after filtration and washings with $\mathrm{Et}_{2} \mathrm{O}$.

4a (a mixture of two isomers (2:1)): ${ }^{1} \mathrm{H}$ NMR (300 MHz, $\left.\mathrm{CDCl}_{3}\right) \delta 7.99(\mathrm{~d}, \mathrm{~J}=7.9 \mathrm{~Hz}, 0.5 \mathrm{H}) / 7.83-7.80(\mathrm{~m}, 0.5 \mathrm{H})$, 7.50-7.46 (m, $1 \mathrm{H}), 7.35-7.16(\mathrm{~m}, 5 \mathrm{H}), 7.11-6.99(\mathrm{~m}, 4 \mathrm{H})$, $6.76-6.63(\mathrm{~m}, 3 \mathrm{H}), 6.58-6.53(\mathrm{~m}, 1 \mathrm{H}), 5.21(\mathrm{~d}, \mathrm{~J}=10.1 \mathrm{~Hz}$, $0.33 \mathrm{H}) / 5.01(\mathrm{~d}, \mathrm{~J}=9.0 \mathrm{~Hz}, 0.67 \mathrm{H}), 3.63-3.50(\mathrm{~m}, 2 \mathrm{H})$.

9a (2,3-trans-2,4-cis isomer): TLC (EtOAc/hexane (10:90)) $\mathrm{R}_{\mathrm{f}}=0.55 ; \mathrm{mp} 120-122{ }^{\circ} \mathrm{C} ;{ }^{1} \mathrm{H}$ NMR $\left(300 \mathrm{MHz}, \mathrm{CDCl}_{3}\right) \delta 7.32-$ $7.12(\mathrm{~m}, 11 \mathrm{H}), 7.04-6.98(\mathrm{~m}, 3 \mathrm{H}), 6.65-6.58(\mathrm{~m}, 2 \mathrm{H}), 6.45-$ $6.37(\mathrm{~m}, 3 \mathrm{H}), 4.75(\mathrm{~d}, \mathrm{~J}=9.7 \mathrm{~Hz}, 1 \mathrm{H}, \mathrm{H}-4), 3.90-3.80(\mathrm{~m}, 3$ $\mathrm{H}), 3.07(\mathrm{t}, \mathrm{J}=9.7 \mathrm{~Hz}, 1 \mathrm{H}, \mathrm{H}-3), 2.73(\mathrm{dd}, \mathrm{J}=13.5,2.5 \mathrm{~Hz}$, $1 \mathrm{H}), 2.41(\mathrm{dd}, \mathrm{J}=13.5,10.7 \mathrm{~Hz}, 1 \mathrm{H}) ;{ }^{13} \mathrm{C} \mathrm{NMR}(75 \mathrm{MHz}$, $\left.\mathrm{CDCl}_{3}\right) \delta 147.8,143.6,141.0,138.2,129.1,129.0,128.8,128.8$, $128.4,128.0,127.1,126.7,124.0,117.7,117.2,114.0,113.5$, 57.5, 57.4, 50.9, 41.0; IR (KBr) 3403, 1600, $1494 \mathrm{~cm}^{-1}$; MS m/z (rel intensity) $390\left(3, \mathrm{M}^{+}\right), 294$ (100), 206 (92); HRMS calcd for $\mathrm{C}_{28} \mathrm{H}_{26} \mathrm{~N}_{2}\left(\mathrm{M}^{+}\right)$390.2096, found 390.2095. Anal. Calcd for $\mathrm{C}_{28} \mathrm{H}_{26} \mathrm{~N}_{2}$ : C, 86.12; $\mathrm{H}, 6.71 ; \mathrm{N}, 7.17$. Found: C, 86.26; $\mathrm{H}, 6.76$; $\mathrm{N}, 7.00$.

9a (2,3-cis-2,4-cis isomer): TLC (EtOAc/hexane (10:90)) $\mathrm{R}_{\mathrm{f}}$ $=0.58 ; \mathrm{mp} \mathrm{200-202}{ }^{\circ} \mathrm{C} ; \mathrm{IR}(\mathrm{KBr}) 3403,1600 \mathrm{~cm}^{-1} ;{ }^{1} \mathrm{H} \mathrm{NMR}$ $\left(300 \mathrm{MHz} \mathrm{CDCl}_{3}\right) \delta 7.28-7.06(\mathrm{~m}, 14 \mathrm{H}), 6.77-6.69(\mathrm{~m}, 2 \mathrm{H})$, $6.63(\mathrm{~d}, \mathrm{~J}=7.6 \mathrm{~Hz}, 2 \mathrm{H}), 6.49(\mathrm{~d}, \mathrm{~J}=8.0 \mathrm{~Hz}, 1 \mathrm{H}), 4.46(\mathrm{br} \mathrm{s}$, $1 \mathrm{H}, \mathrm{H}-4), 3.87-3.81(\mathrm{~m}, 2 \mathrm{H}), 3.29(\mathrm{br} \mathrm{d}, \mathrm{J}=3.0 \mathrm{~Hz}, 1 \mathrm{H}$, $\mathrm{H}-3$ ), 2.79 (dd, J = 13.5, 3.0 Hz, $1 \mathrm{H}$ ), 2.20 (dd, J = 13.5, 11.1 $\mathrm{Hz}, 1 \mathrm{H}) ;{ }^{13} \mathrm{C} N M R\left(75 \mathrm{MHz} \mathrm{CDCl}_{3}\right) \delta 146.1,145.0,139.3$, $138.3,131.5,129.5,129.4,129.1,128.8,128.6,128.4,126.9$ $126.7,120.8,118.3,117.4,114.8,112.6,54.9,50.9,48.2,39.9$; MS m/z (rel intensity) 390 (2, M+), 294 (13), 206 (100); HRMS Calcd for $\mathrm{C}_{28} \mathrm{H}_{26} \mathrm{~N}_{2}\left(\mathrm{M}^{+}\right)$390.2096, found 390.2090. Anal. Calcd for $\mathrm{C}_{28} \mathrm{H}_{26} \mathrm{~N}_{2}$ : C, 86.12; $\mathrm{H}, 6.71 ; \mathrm{N}, 7.17$. Found: C, 85.81; $\mathrm{H}$, 6.65; N, 6.78 .

(2S,3R,4R )-4-Anilino-1,4-dihydro-2, 2'-dimethyl-2-[(4S)2,2-dimethyl-1,3-dioxolan-4-yl]-2H-spiro[1',3'-dioxolane4',3-quinoline] (9j). To a solution of (R)-glyceraldehyde acetonide ( $1.3 \mathrm{~g}, 10 \mathrm{mmol})$ and benzotriazole (1.19 g, $10 \mathrm{mmol}$ ) in $\mathrm{EtOH}(5 \mathrm{~mL})$ was added a solution of aniline $(0.93 \mathrm{~g}, 10$ $\mathrm{mmol})$ in $\mathrm{EtOH}(2 \mathrm{~mL})$. The mixture was stirred at $25^{\circ} \mathrm{C}$ for

(17) Hartman, G. D.; Phillips, B. T.; Halczenko, W. J . Org. Chem. 1985, 50, 2423. 
$16 \mathrm{~h}$ and then kept at $-5^{\circ} \mathrm{C}$ for $2 \mathrm{~h}$. The solids were filtered, washed with $\mathrm{Et}_{2} \mathrm{O}$, and dried to give the benzotriazole derivative $4 \mathbf{j}(2.75 \mathrm{~g}, 77 \%)$ as a mixture of regio- and diastereoisomers as indicated by the ${ }^{1} \mathrm{H}$ NMR analysis: ${ }^{1} \mathrm{H}$ NMR $(300 \mathrm{MHz}$, $\left.\mathrm{CDCl}_{3}\right) \delta$ 8.03-7.97 (m, 0.5 H), 7.85-7.73 (m, $\left.1.5 \mathrm{H}\right), 7.43-$ $7.31(\mathrm{~m}, 2 \mathrm{H}), 7.12-7.04(\mathrm{~m}, 2 \mathrm{H}), 6.77-6.63(\mathrm{~m}, 3 \mathrm{H}), 6.35-$ $6.23(\mathrm{~m}, 1 \mathrm{H}), 5.11(\mathrm{br} \mathrm{d}, \mathrm{J}=9.3 \mathrm{~Hz}, 1 \mathrm{H}), 4.82-4.66(\mathrm{~m}, 1 \mathrm{H})$, 4.26-3.93 (m, 2 H), $1.57(\mathrm{~s}, 1 \mathrm{H}), 1.53(\mathrm{~s}, 0.5 \mathrm{H}), 1.43(\mathrm{~s}, 0.5$ $\mathrm{H}), 1.37(\mathrm{~s}, 1.5 \mathrm{H}), 1.31(\mathrm{~s}, 1.5 \mathrm{H}), 1.15(\mathrm{~s}, 1 \mathrm{H})$.

Under an atmosphere of argon, a deep blue $\mathrm{Sml}_{2}$ solution $(0.1 \mathrm{M})$ was prepared from samarium metal ( $45 \mathrm{mg}, 0.3 \mathrm{mmol}$ ) and 1,2-diiodoethane ( $70.5 \mathrm{mg}, 0.25 \mathrm{mmol})$ in anhydrous THF $(2.5 \mathrm{~mL})$. The solution was cooled to $-78^{\circ} \mathrm{C}$. A THF solution $(3 \mathrm{~mL})$ of $4 \mathbf{j}(810 \mathrm{mg}, 2.5 \mathrm{mmol})$ was added dropwise. The mixture was stirred at $-78{ }^{\circ} \mathrm{C}$ for $5.5 \mathrm{~h}$, warmed to room temperature, and maintained over a period of $16 \mathrm{~h}$. Saturated solution of $\mathrm{K}_{2} \mathrm{CO}_{3}(0.1 \mathrm{~mL})$ was added, after which the mixture was filtered through a pad of silica gel and rinsed with EtOAc/ hexane (1:1). The filtrate was concentrated and purified by column chromatography $\left(\mathrm{SiO}_{2}\right)$ using EtOAc/hexane (15:85) to yield a pure THQ 9j (455 mg, 88\%).

9j: TLC (EtOAc/hexane $(20: 80)) \mathrm{R}_{\mathrm{f}}=0.58 ; \mathrm{mp} 150-152^{\circ} \mathrm{C}$; $[\alpha]^{28} \mathrm{D}-186.2\left(\mathrm{c}=0.65, \mathrm{CHCl}_{3}\right) ; \mathrm{IR}(\mathrm{KBr}) 3416,1603 \mathrm{~cm}^{-1} ;{ }^{1} \mathrm{H}$ NMR (300 MHz, CDCl $\left.{ }_{3}\right) \delta 7.20-7.13(\mathrm{~m}, 2 \mathrm{H}), 7.07-7.03(\mathrm{~m}$,
$2 \mathrm{H}), 6.80-6.71(\mathrm{~m}, 3 \mathrm{H}), 6.61-6.56(\mathrm{~m}, 2 \mathrm{H}), 4.44(\mathrm{~s}, 1 \mathrm{H})$ 4.39-4.33 (m, $1 \mathrm{H}), 4.23(\mathrm{~d}, \mathrm{~J}=9.5 \mathrm{~Hz}, 1 \mathrm{H}), 4.19-4.14(\mathrm{~m}, 1$ $\mathrm{H}), 4.07-4.03(\mathrm{~m}, 1 \mathrm{H}), 3.66(\mathrm{~d}, \mathrm{~J}=9.5 \mathrm{~Hz}, 1 \mathrm{H}), 3.56(\mathrm{~d}, \mathrm{~J}=$ $6.9 \mathrm{~Hz}, 1 \mathrm{H}), 1.53(\mathrm{~s}, 6 \mathrm{H}), 1.43(\mathrm{~s}, 3 \mathrm{H}) 1.37(\mathrm{~s}, 3 \mathrm{H}) ;{ }^{13} \mathrm{C} N M R$ $\left(75 \mathrm{MHz}_{1} \mathrm{CDCl}_{3}\right) \delta 147.8,142.6,130.0,129.2,128.9,121.6$, $118.3,117.8,114.5,110.5,109.1,82.4,74.1,68.8,68.5,59.8$, 55.1, 26.9, 26.8, 26.5, 25.0; MS m/z (rel intensity) $410\left(54, \mathrm{M}^{+}\right)$, 319 (100); HRMS calcd for $\mathrm{C}_{24} \mathrm{H}_{30} \mathrm{~N}_{2} \mathrm{O}_{4}\left(\mathrm{M}^{+}\right)$410.2206, found 410.2213. Anal. Calcd for $\mathrm{C}_{24} \mathrm{H}_{30} \mathrm{~N}_{2} \mathrm{O}_{4}: \mathrm{C}, 70.22 ; \mathrm{H}, 7.37 ; \mathrm{N}$, 6.82. Found: $\mathrm{C}, 69.90 ; \mathrm{H}, 7.33 ; \mathrm{N}, 6.75$. The structure of $9 \mathrm{j}$ was confirmed by an X-ray diffraction analysis.

Acknowledgment. We thank the National Science Council for financial support. One of us (S.T.) thanks NSC for a postdoctoral fellowship.

Supporting Information Available: Additional experimental procedures, spectral data, and ${ }^{1} \mathrm{H}$ and ${ }^{13} \mathrm{C}$ NMR spectra of some selected compounds, as well as the crystal data, bond distances, bond angles, and ORTEP drawings of compounds 9f, $\mathbf{9 j}$, and $\mathbf{9 n}$. This material is available free of charge via the Internet at http://pubs.acs.org.

J $0000033 x$ 